\title{
The possible ameliorative role of mesenchymal stem cells and curcumin on the lung in experimentally induced type I diabetes: Histological and immunohistochemical study
}

Original Article

\author{
Amany Elsayed Mohammed Hamoud ${ }^{1}$, Hala Gabr Metwally ${ }^{2}$ \\ Departments of ${ }^{1}$ Anatomy and Embryology and ${ }^{2}$ Clinical Pathology, Faculty of Medicine, \\ Cairo University, Cairo, Egypt
}

\begin{abstract}
Background: Type 1 diabetes mellitus affects lungs due to poor glycemic control. Improvement in both lung function and architecture in experimentally-induced lung injury that received exogenous AMSCs by different mechanisms was found. Curcumin has a potent antioxidant and antifibrotic function.

Objective: The current study was designed to elucidate the possible ameliorative role of mesenchymal stem cells and curcumin on the lung in experimentally induced type I diabetes by histological and immunohistochemical study.

Materials and Methods:Twenty six adult albino rats were divided into five groups: donor, control group, curcumin group and adipose derived mesenchymal stem cell (AMSCs) group. Group II (diabetic group) received a single dose STZ $50 \mathrm{mg} / \mathrm{kg} / \mathrm{day}$, group III received STZ and powdered diet supplemented with $0.05 \%$ curcumin, group IV received STZ and $1 \times 106$ of cultured and labelled rat AMSCs. Lung sections were subjected to histological, morphometric, biochemical and statistical studies.

Results: Diabetes induced histological changes in lung in the form of inflammatory changes in bronchiole, a sig increase in the thickness of interalveolar septa, thickness of the vessels wall, area \% of collagen and count CD105+ve cells. Sig decrease in antioxidant activity and sig increase in oxidant enzymes. Sig increase in L-hydroxyproline(L-hyp) level as well STAT and SMAD genes. Administration of curcumin and AMSCs improved sig the previous changes.

Conclusion: Diabetes induced lung injuries in rats that was ameliorated by by curcumin, but AMSCs have more pronounced effect than curcumin therapy.
\end{abstract}

Key Words:ADMSCs, antioxidant, curcumin, diabetes, lung.

Received: 29 July 2019, Accepted: 28 August 2019

Corresponding Author: Amany Elsayed Hamoud, Department of Anatomy, Faculty of Medicine, Cairo University,Cairo, Egypt, Tel.: 01020364428, E-mail: dramanyhamoud@gmail.com

ISSN: 2536-9172, June 2019, Vol. 3, No. 1

\section{INTRODUCTION}

Type 1 diabetes mellitus affects many organs, including heart, lung, kidney, retina, liver, and skeletal muscle due to poor glycemic control. The exact mechanism of lung affection (either fibrotic or inflammatory lesion) in diabetic patients remain unclear ${ }^{[1]}$.

Pancreatic islet transplantation is an excellent option for treatment of patient with uncontrolled hypoglycaemia despite of insulin treatment, however this approach is inaccessible due to limited donors and the adverse side effect of life-long immunosuppressive treatment ${ }^{[2]}$.

Stem cells are highly specialized cells and the most promising therapies in many tissues regeneration as they are easy to differentiate into a number of cell types that make up the body tissues and organs. Mesenchymal stem cells (MSCs) can be isolated and expanded with high efficiency from several adult and foetal tissues including bone marrow, adipose tissue, dental pulp and umbilical cord blood ${ }^{[3]}$.

Different studies have used streptozotocin (STZ) to induce type 1 diabetes mellitus in laboratory animals. The single diabetogenic dose of STZ has been documented in different studies from $50 \mathrm{mg} / \mathrm{kg}$ b/w up to $70 \mathrm{mg} / \mathrm{kg}$. The cytotoxic action of STZ is mediated by reactive oxygen species $^{[4]}$.

The improvement in both lung function and architecture in experimentally-induced lung injury in either animal models that received exogenous MSCs or MSC-conditioned media might have different mechanisms. Adipose-derived mesenchymal stem cells(AMSCs) play a potential role in stem cell transplantation in animal models ${ }^{[5]}$. 
Curcumin is a potent antioxidant as it protects against streptozotocin-induced oxidative stress by scavenging free radicals, well-known anti-inflammatory, antimicrobial, antiproliferative as well as anti-atherosclerotic effects. Also, its antifibrotic role in liver, kidney and lung of experimental animal has been documented ${ }^{[6]}$.

The aim of the present study was to elucidate the possible ameliorative role of AMSCs and curcumin on the lung in induced type I diabetes mellitus in adult male rats.

\section{PATIENTS AND METHODS}

\section{Animals:}

The current study was carried out on 26 adult male albino rats aged three to five months and weighing about 180-230 grams were used in this study. The rats were obtained from Animal House of Kasr-Alainy, Faculty of Medicine, Cairo University. Rats were housed for one week for environmental adaptation under standard laboratory conditions at $22-24{ }^{\circ} \mathrm{C}$ with 12 hours lightldark cycle. They were fed on a constant adequate nutrition diet and allowed free access to drinking water ad libitum. The experimental work was conducted in accordance with the guidelines of the animals committee at Cairo University. They were housed in cages, six rats/cage. The rats were divided into five groups as follow (six rats each):

- Donor Group: Two rats were used for stem cell isolation, culture, phenotyping and labeling.

- Group I (Control group): Two rats received a single intraperitoneal (IP) injection of $0.5 \mathrm{ml}$ citrate buffer, two rats received $1 \mathrm{ml}$ PBS intravenously, and two rats received powdered diet supplemented with $0.05 \%$ curcumin.

- Group II (Diabetic group): Received a single dose of STZ (Sigma Company, St. Louis, Mo, USA) in a powder form as $1 \mathrm{~g}$ vial in a dose of $50 \mathrm{mg} / \mathrm{kg} /$ day dissolved in $0.5 \mathrm{ml}$ sodium citrate buffer IP for each rat. Three days following STZ injection, diabetes was confirmed by measuring the blood glucose level. The animals were considered diabetic if their blood glucose levels were higher than $200 \mathrm{mg} / \mathrm{dl}^{[7]}$. The animals were sacrificed four weeks following diabetes confirmation.

- Group III (Curcumin group): Rats were subjected to diabetes induction as in group II, on the day following confirmation of diabetes, they received their powdered diet supplemented with $0.05 \%$ curcumin (w/w). The animals were sacrificed four weeks following curcumin $\operatorname{administration}^{[8]}$.

- Group IV (AMSCs Group):. Rats were subjected to diabetes induction as in group II , on the day following diabetes confirmation, $1 \times 106$ of cultured and labelled rat AMSCs, suspended in $1 \mathrm{ml}$ PBS, were injected into the tail vein on two successive days. Then the animals were sacrificed after four weeks ${ }^{[9]}$.

\section{Methods:}

All rats were sacrificed by cervical dislocation ${ }^{[10]}$ using IP injection of phenobarbitone sodium $(60 \mathrm{mg} / \mathrm{kg})^{[11]}$. Central ventral midline incision was performed for each animal. The lung were removed and sections were fixed in $10 \%$ formol saline for 48 hours. Paraffin blocks and $5 \mu \mathrm{m}$ thick sections were prepared. Sections were subjected to:

- Histological study: Haematoxylin and Eosin (H\&E) stain $^{[12]}$ and Masson's trichrome stain ${ }^{[13]}$.

- Histochemical study: Sections were stained with Prussian blue (PB) stain for demonstration of iron oxide labelled therapeutic stem cells (SCs) ${ }^{[14]}$.

- Immunohistochemical study: CD105 immuno staining is the marker for MSCs. $0.1 \mathrm{ml}$ prediluted primary antibody (CD105) rabbit polyclonal $\mathrm{Ab}(\mathrm{ab} 27422)$ that incubated at room temperature in moist chamber for 30-60 minutes. Tonsils were used as positive control specimens. Cellular localization is the cell membrane. One of the lung sections was used as a negative control by passing the step of applying the primary antibody ${ }^{[15]}$.

- Morphometric study: Thickness of the alveolar septa and the thickness of pulmonary vessels (indicated by the distance parameter) were measured in H\&E stained sections. The area percentage of collagen fibers were done in Masson's trichrome sections. The count of CD105 +ve cells were assessed using interactive measurements menu. These measurements were done in 10 high power fields (HPF) in control and experimental groups.

\section{Chemical parameters:}

A. Oxidative and antioxidative parameters: Measurement of malanodialdehyde (MDA), glutathione (GSH) and catalase(CAT) activity: Half of the specimens were kept in the deep freezer for homogenization.1gm of specimen was homogenized in $10 \mathrm{ml}$ normal saline by using homogenizer (Ortoalresa, Spain). Then centrifuged at $1000 \mathrm{Xg}$ for about 10 minutes. It was collected in and kept in the deep freezer $\left(\right.$ at $-20^{\circ} \mathrm{C}$ ) reduced GSH, CAT and $\mathrm{MDA}^{[16]}$

B. Tumor necrosis factor $\alpha$ (TNF- $\alpha$ ): Quantitive determination in lung homogenate, was measured by use of TNF- $\alpha$ ELISA kit (R\&D Systems, Inc., USA) according to the manufacturers' manual[ ${ }^{[17]}$.

C. Hydroxyproline (L-hyp): L-hyp content was quantified colorimetrically from lung tissue homogenate samples by using the chloramine $\mathrm{T}$ method ${ }^{[18]}$. 
- Quantitative polymerase chain reaction (qPCR) of SMAD gene and Signal transducer and activator of transcription (STAT) genes: Rat primer SMAD gene ${ }^{[1]}$, rat primer STAT gene ${ }^{[19]}$ : Formalin-fixed paraffin-embedded (FFPE) lungs specimens by qPCR were performed ${ }^{[20]}$. Reverse Transcription is carried out with the SuperScript First-Strand Synthesis System for reverse transcriptase (RT)-PCR. Ribonucleic acid (RNA)/primer mixture was prepared: $5 \mu \mathrm{g}$ total RNA and $3 \mu \mathrm{l}$ random hexamers. The specimens were put at $65^{\circ} \mathrm{C}$ for $5 \mathrm{~min}$ and ice for only one min. Reaction master mixture was prepared for each reaction then added to the RNA/primer mixture and mixed briefly, after that placed at room temperature two minutes. $1 \mu \mathrm{l}$ (50 units) of SuperScript II RT was added to each tube, mixed and incubated at $25^{\circ} \mathrm{C}$ for 10 min. The tubes were incubated at $42^{\circ} \mathrm{C}$ for $50 \mathrm{~min}$, heat inactivated at $70^{\circ} \mathrm{C}$ for $15 \mathrm{~min}$, and then chilled on ice. $1 \mu \mathrm{l}$ RNAase $\mathrm{H}$ was added and incubated at $37^{\circ} \mathrm{C}$ for 20 min. The 1 st strand complementary deoxyribonucleic acid (cDNA) was stored at $-20^{\circ} \mathrm{C}$ until use for real-time PCR. The primer concentrations were normalized, genespecific and reverse primer pair were mixed. A copy of the setup file was saved and all PCR cycles were deleted (used for later dissociation curve analysis). $50^{\circ} \mathrm{C} 2 \mathrm{~min}, 1$ cycle, $95^{\circ} \mathrm{C} 10 \mathrm{~min}, 1$ cycle, $95^{\circ} \mathrm{C} 15$ seconds $->60^{\circ} \mathrm{C} 30$ seconds -> $72{ }^{\circ} \mathrm{C} 30$ seconds, 40 cycles and $72^{\circ} \mathrm{C} 10$ min, 1 cycle. A real-time PCR reaction mixture can be either $50 \mu \mathrm{l}$ or $25 \mu \mathrm{l}$. After PCR is finished, the tubes were removed from the machin (Table 1).

\section{Mesenchymal stem cells preparation:}

1. Adipose derived mesenchymal stem cells (AMSCs) isolation and culture ${ }^{[21]}$ : The precipitate was resuspended and plated onto a cell culture dish (Corning, NY, USA) at a density of 105 cells $/ \mathrm{ml}$ in fresh Dulbecco's modified Eagle's medium (DMEM)/F-12 (Invitrogen) supplemented with $1 \%$ penicillin/streptomycin (SigmaAldrich, St. Louis, MO, USA) and 10\% fetal bovine serum (FBS) (Hyclone, Logan, UT, USA). Cell cultures were maintained in a standard humidified incubator, saturated by $5 \% \mathrm{CO} 2$, at $37 \mathrm{C}^{\circ}$. Twenty four hours later, the nonadherent cells were eliminated by changing the culture medium. The adherent cells were expanded by serial passages, and ADMSCs from 3 to 5 passages were used.

2. Labelling: AMSCs were labelled by incubation with ferumoxides injectable solution ( 25 microgram $\mathrm{Fe} /$ ml, Feridex, Berlex Laboratories) in culture medium for 24 hours with 375 nanogram $/ \mathrm{ml}$ poly L lysine that added one hour before the incubation. Then it was assessed histologically using Prussian blue. Feridex labelled AMSCs were washed in PBS, trypsinized, washed and resuspended in $0.01 \mathrm{Mol} / \mathrm{L} \mathrm{PBS}$ at concentration of $1 \times 1,000,000$ cells/ $\mathrm{ml}^{[22]}$.
3. Viability: Was done using trypan blue dye exclusion test. This method is based on that the viable cells do not accept certain dyes, while dead cells receive ${ }^{[23]}$.

4. Flow cytometry: Flow cytometric analyses were performed on a Fluorescence Activated Cell Sorter (FACS) flow cytometer (Coulter Epics Elite, Miami, FL, USA). MSCs were trypsinized and washed twice with PBS. A total number of $1 \times 105$ HMSC were used for each run. To evaluate the MSCs marker profile, cells were incubated in $100 \mu \mathrm{L}$ of PBS with $3 \mu \mathrm{L}$ of CD105-FITC for $20 \mathrm{~min}$ at room temperature. Antibody concentration was $0.1 \mathrm{mg}$ $\mathrm{mL}-1^{[24]}$. Cells were washed twice with PBS and finally diluted in $200 \mu \mathrm{L}$ of PBS. The expression of surface marker was assessed by the mean fluorescence. CD105 (MSCs marker). The percentage of cells positive for CD 105 was determined by subtracting the percentage of cells stained non-specifically with isotype control antibodies.

- Statistical study: Quantitative data were summarized as means and standard deviations and compared using one-way analysis-of-variance (ANOVA). Any significant(sig) ANOVA was followed by post hoc Tukey test to detect which pairs of groups caused the sig difference. P-values $<0.05$ were considered statistically $\operatorname{sig}^{[25]}$. Calculations were made on Statistical Package of Social Science (SPSS) software version 16.

\section{RESULTS}

\section{Histological and Histochemical changes :}

- Haematoxylin and Eosin (H\&E) stained sections: Section in the lung of a control rat showing normal appearance of bronchioles, venule, alveoli and alveolar sacs (Plate 1a). Closer observation showed normal appearance of alveoli, alveolar sacs lined mainly by pneumocytes type I with flat nuclei and interalveolar septa exhibiting pulmonary capillaries (Plate 1b). Section in the lung of diabetic rats revealed a small bronchiole with partially obliterated lumen by multiple shed cells and surrounded by dense infiltration. Some shed epithelial cells were seen in the lumen of a part of another bronchiole. Moreover, thickening of the interalveolar septa and congested thickened vessel wall were found (Plate 1.C,d). Closer observation of the diabetic group showed mononuclear cell infiltrating cells including fibroblasts in thickened interalveolar septa and alveoli are mainly lined by infiltrating cells (Plate 1e). Section in the lung of diabetic rats treated with curcumin showed less thickening of interalveolar septa with partial thickening of a vessel wall and less dense infiltrating cells in the interalveolar septa. Some normal alveoli and alveolar sacs lined by multiple pneumocytes type (Plate 1f and Plate 2a). Sections in the lung of 
diabetic rats treated with AMSCs showed a bronchiole with few shed epithelial cells, a congested arteriole and a congested venule (Plate.2b). Closer observation revealed apparently normal alveoli and alveolar sacs lined by numerous pneumocytes type I (Plate.2c).

- Masson's trichrome stained sections: Section in the lung of a control rat showed fine collagen fibers in the interalveolar septa. While, the collagen fibers were increased in the diabetic group with thickening in the interalveolar septa. In the lung of a diabetic rat treated with curcumin showed less collagen fibers in the interalveolar septa. In the lung of a diabetic rat treated with AMSCs fine collagen fibers were found in the interalveolar septa and around pulmonary capillaries (Plate 3. a,b,c,d).

- Prussian blue stained sections: Section in the lung of a control rat, diabetic and adiabetic rat treated with curcumin showed negative staining among alveoli and alveolar sacs. But in the lung of a diabetic rat there was thickening in the interalveolar septa. Section in the lung of a diabetic rat treated with AMSCs showed +ve staining of spindle cells among alveoli, alveolar sacs and minimally thickened interalveolar septa (Plate 4.a,b,c,d).

- CD105 immunostaining staining sections: Section in the lung of a control rat showed negative IE. Section in the lung of a diabetic rat showed few CD105+ve spindle cells in thickened interalveolar septa. Section in the lung of a diabetic rat treated with curcumin showed some CD105+ve spindle cells in less thickened interalveolar septa. Section in the lung of a diabetic rat treated with SCs showed multiple CD105+ve spindle cells in minimally thickened interalveolar septa (Plate 5.a,b,c,d).

\section{Morphometric Results:}

- Thickness of the interalveolar septa: By the application of two way ANOVA test, results of the mean thickness $(\mu)$ of the interalveolar septa in haematoxylin and eosin stained sections was studied in different experimental groups. A sig increase $(P<0.05)$ was found in the diabetic group compared to control, curcumin and SC therapy group. In addition a sig decrease was detected in curcumin compared to diabetic group, and in AMSCs group compared to curcumin and diabetic groups (Table 2).
- Thickness of the wall of the vessels of the lung: In the control group, the mean thickness $(\mu)$ of the wall of the pulmonary vessels measured in haematoxylin and eosin stained sections. The mean thickness assessed indicated a sig increase $(P<0.05)$ in diabetic group compared to the other groups and in curcumin group compared to control and AMSCs groups (Table 2).

- Area \% of collagen fibers: In control group, the mean area $\%$ of collagen fibers found in the interalveolar septa was measured by examination of Masson's trichrome stained sections. The values recorded indicated a sig increase $(P<0.05)$ in diabetic group compared to the other groups and in curcumin group compared to control and AMSCs groups (Table 2).

- Count of CD 105+ve cells: In diabetic group, the mean count of CD105 +ve cells found was assesed by examination of immune-stained sections. The mean values indicated a sig increase $(P<0.05)$ in AMSCs group compared to the other two groups and in curcumin group compared to diabetic group (Table 2).

\section{Chemical changes results:}

- Oxidative and antioxidative parameter changes: In diabetic group, GSH and CAT values were sig decreased compared to the other groups, while, MDA was sig increased. In curcumin group a sig decrease was found in MDA value and a sig increase was detected in CAT and GSH values compared to the diabetic group. On the other hand, in AMSCs group a sig decrease was found in MDA value and a sig increase was detected in CAT and GSH values compared to the diabetic and curcumin groups.

- SMAD and STAT genes: Sig increase was found in both STAT and SMAD genes in diabetic group compared to the other groups. While, a sig decrease was found in curcumin group compared to diabetic group, and in AMSCs group compared to diabetic and curcumin groups.

- TNF $\alpha$ and L-hyp: Sig increase was found in both TNF $\alpha$ and L-hyp in diabetic group compared to other groups. While, a sig decrease was evident in AMSCs group compared to diabetic and curcumin groups (Table 3). 
Table 1:The primer sequence of the studied SMAD and STAT gene

Primer sequence

SMAD

Forward: 5'-AAATGACAGCAGCAGGGACACTA-3'.

Reverse: : 5'-TGAGGAGGTAGGACCCACAGTAGA-3'.

STAT

Forward : 5'- TGGAAGAGGCGGCAGCAGATAGC-3',

Reverse : 5'CACGGC CCCCATTCCCACAT-3'.

Table 2: Mean \pm standard deviation (SD) of the thickness of interalveolar septa (IAS), thickness of the wall of pulmonary vessels (T), area $\%$ of collagen fibers $(\mathrm{CF})$ and count of CD $105+$ ve cells in different groups

\begin{tabular}{|c|c|c|c|c|}
\hline Groups & Thickness of IAS & $\begin{array}{c}\mathrm{T} \text { of wall of } \\
\text { pulmonary vessels }\end{array}$ & Area $\%$ of $\mathrm{CF}$ & $\begin{array}{c}\text { Count of CD105 } \\
+ \text { ve cells }\end{array}$ \\
\hline Control group & $23.37 \pm 3.93$ & $4.08 \pm 0.86$ & $1.18 \pm 0.21$ & ---------- \\
\hline Diabetic group & $106.73 \pm 7.39^{*}$ & $35.59 \pm 0.97^{*}$ & $24.13 \pm 3.46^{*}$ & $6.18 \pm 0.21^{*}$ \\
\hline Curcumin group & $55.57 \pm 3.83^{\wedge}$ & $18.90 \pm 2.02^{\wedge}$ & $4.18 \pm 1.08^{\wedge}$ & $11.13 \pm 3.46^{\wedge}$ \\
\hline AMSCs group & $29.97 \pm 3.13 \#$ & $7.40 \pm 13.23 \#$ & $2.72 \pm 0.45 \#$ & $20.18 \pm 1.08 \#$ \\
\hline
\end{tabular}

* sig compared to all groups.

$\wedge$ sig compared to diabetic group.

\# sig compared to diabetic and curcumin groups.

Table(3): Mean change in oxidative, STAT, SMAD genes, TNF $\alpha$ and 1-hyp in different groups

\begin{tabular}{lccccccc}
\hline Group & MDA & GSH & CAT & STAT & SMAD & TNF $\alpha$ & L-hyp \\
\hline Control & $10.8 \pm 1.35$ & $78.3 \pm 20.5$ & $110.8 \pm 30.87$ & $1.00 \pm 0.3$ & $1.05 \pm 0.2$ & $12.9 \pm 3.2$ & $25.8 \pm 7.3$ \\
& & & & & & & \\
Diabetic & $36.0 \pm 5.2^{*}$ & $32.7^{*} \pm 8.3^{*}$ & $58.8^{*} \pm 14.43^{*}$ & $5.45 \pm 1.5^{*}$ & $5.67 \pm 2.1^{*}$ & $78.9 \pm 20.4^{*}$ & $68.5 \pm 19.4^{*}$ \\
& & & & & & & \\
Crucumin & $18.7 \pm 2.71^{\wedge}$ & $55.3 \pm 14.4^{\wedge}$ & $82.5 \pm 25.54^{\wedge}$ & $2.43 \pm 1.3^{\wedge}$ & $2.81 \pm 0.6^{\wedge}$ & $33.6 \pm 10.1^{\wedge}$ & $42.5 \pm 12.45^{\wedge}$ \\
& & & & & & & \\
AMSCs & $12.2 \pm 1.96 \#$ & $70.6 \pm 20.67 \#$ & $100.4 \pm 35.23 \#$ & $1.25 \pm 0.3 \#$ & $1.30 \pm 0.3 \#$ & $16.2 \pm 4.34 \#$ & $29.4 \pm 7.6 \#$ \\
\hline
\end{tabular}

* sig compared to all groups.

$\wedge$ sig compared to diabetic group.

\# sig compared to diabetic and curcumin groups. 


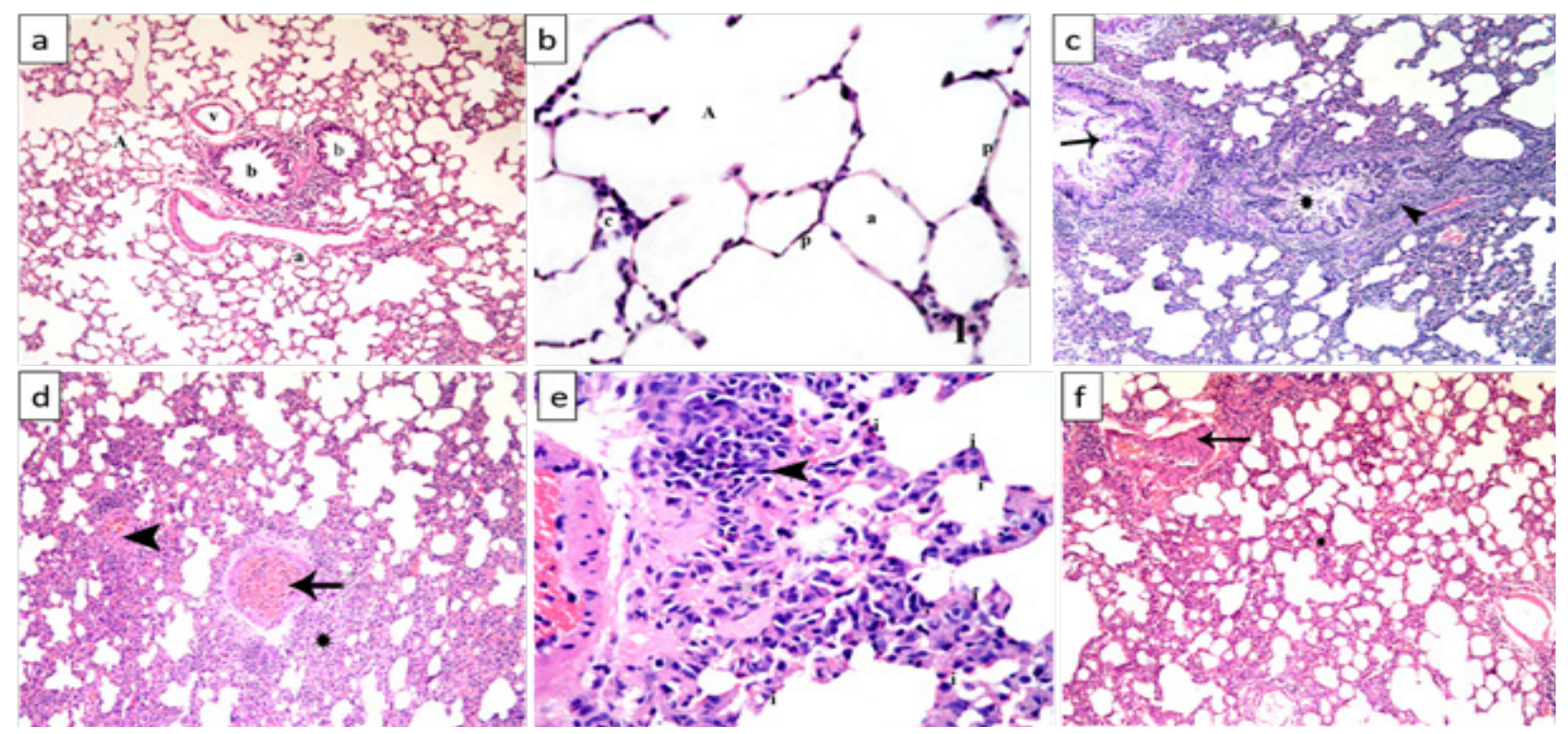

Plate (1): a) section in the lung of a control rat showing two bronchioles (B), a venule (v), alveoli (a), alveolar sacs (A)(H\&E, x 100).b) section in the lung of a control rat showing alveoli (a), alveolar sacs (A)lined mainly by pneumocytes type I(p) and interalveolar septa (I) exhibiting pulmonary capillaries(c)(H\&E, x 400). c) section in the lung of a diabetic rat showing a small bronchiole with partially obliterated lumen by multiple shed cells $\left(^{*}\right)$ and surrounded by dense infiltration (arrowhead). Some shed epithelial cells (arrow) are seen in the lumen of a part of another bronchiole (H\&E, x 100). d) section in the lung of a diabetic rat showing thickening of the interalveolar septa $(*)$. Note a congested vessel (arrow) and another vessel with thickened wall (arrowhead)(H\&E, x 100). e) section in the lung of a diabetic rat showing mononuclear infiltrating cells including fibroblasts (arrowheads) and thickened interalveolar septa (i)(H\&E, x 400). f) section in the lung of a diabetic rat treated with curcumin showing less thickening of interalveolar septa $(*)$. Note partial wall thickening of a vessel (arrow) (H\&E, x 100).

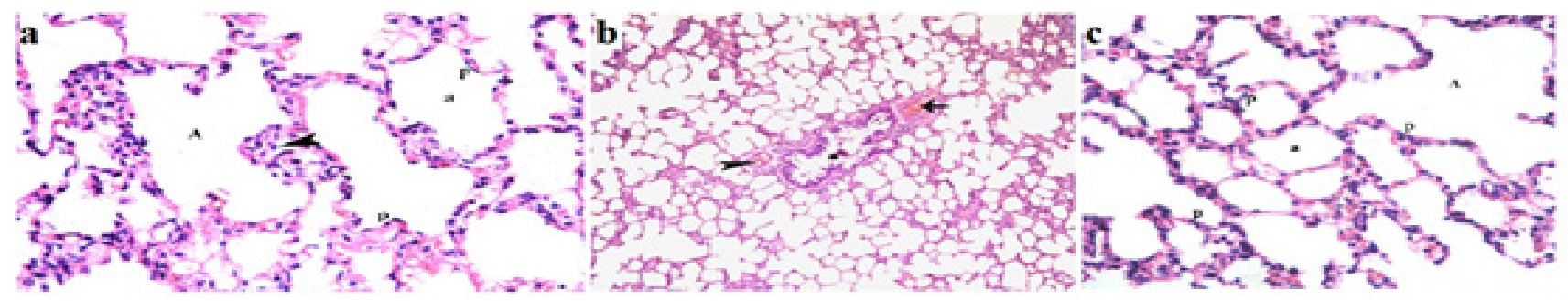

Plate (2): a) section in the lung of a diabetic rat treated with curcumin showing less dense infiltrating cells (arrowhead) in the interalveolar septa. Note normal alveoli (a) and alveolar sacs (A) lined by multiple pneumocytes type I (p)(H\&E, x 400). b) section in the lung of a diabetic rat treated with SCs in showing a bronchiole with few shed epithelial cells $(*)$, a congested arteriole (arrow) and a congested venule (arrowhead).(H\&E, x 100).

c) Section in the lung of a diabetic rat treated with SCs showing apparently normal alveoli (a) and alveolar sacs (A) lined by numerous pneumocytes type I (p)(H\&E, x 400). 


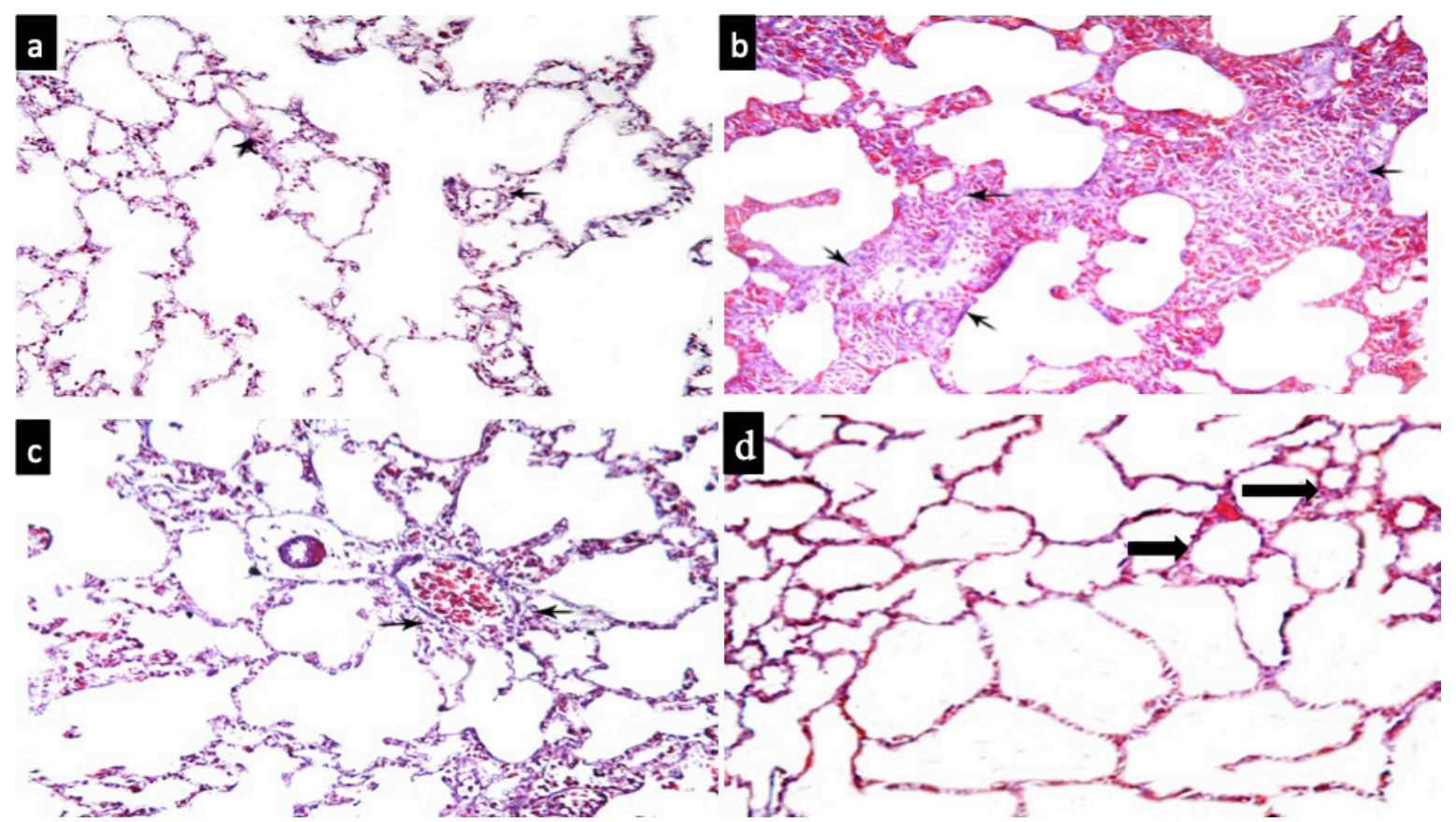

Plate(3): a) section in the lung of a control rat showing fine collagen fibers (arrows) in the interalveolar septa (Masson's trichrome, $\mathrm{x} 200$ ). b)section in the lung of a diabetic rat showing increased collagen fibers (arrows) in thickened interalveolar septa(Masson's trichrome, $\mathrm{x}$ 200). c) section in the lung of a diabetic rat treated with curcumin showing less collagen fibers (arrows)in the interalveolar septa(Masson's trichrome,x200).d)section in the lung of a diabetic rat treated with SCs showing fine collagen fibers (arrows) in the interalveolar septa and around pulmonary capillaries (Masson's trichrome, x 200).

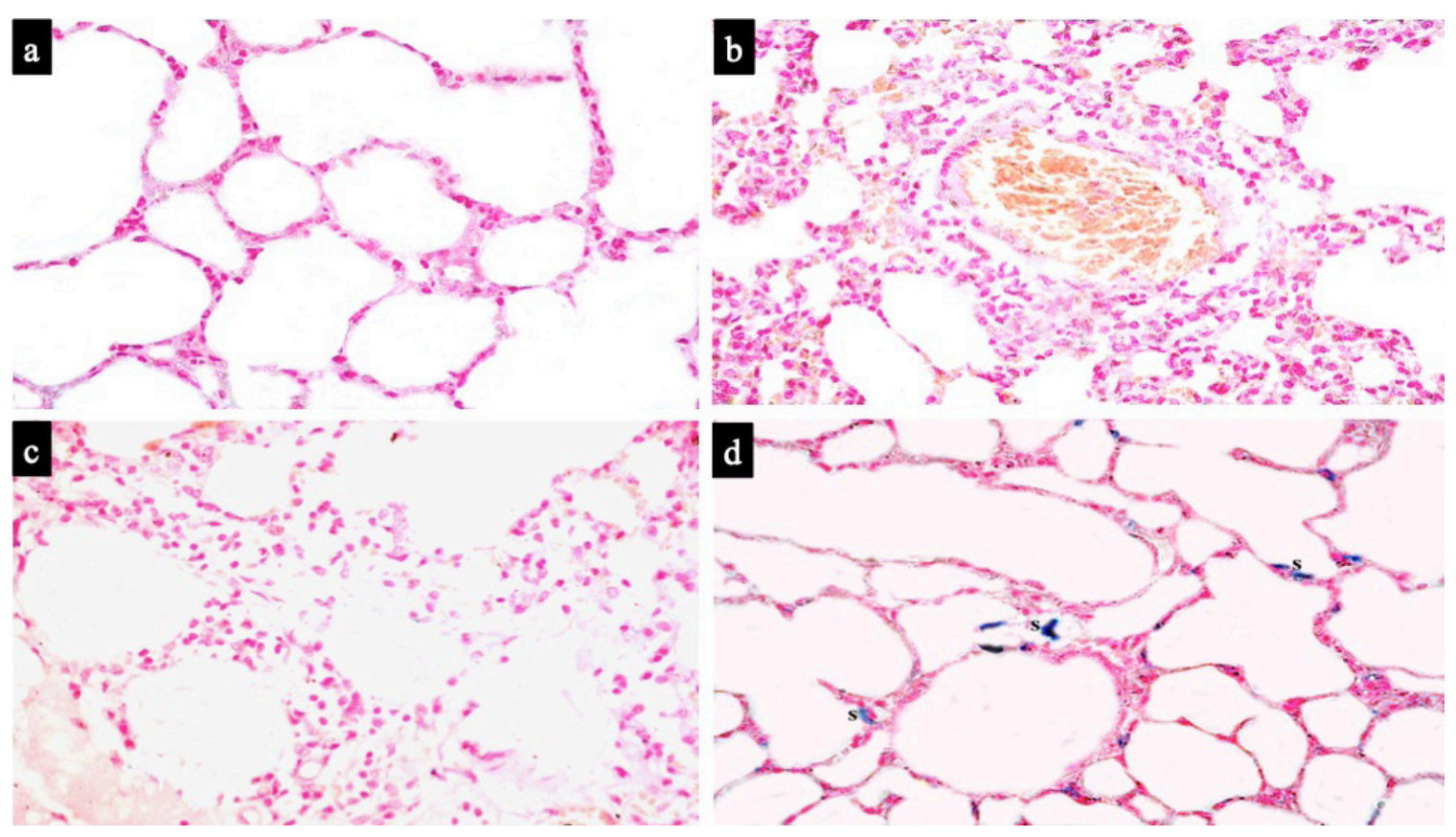

Plate (4): a)section in the lung of a control rat showing negative staining among alveoli and alveolar sacs (Prussian blue, $x 400$ ). b)section in the lung of a diabetic rat showing negative staining among alveoli, alveolar sacs and thickened interalveolar septa (Prussian blue, $\mathrm{x} 400$ ). c) section in the lung of a diabetic rat treated with curcumin showing negative staining among alveoli, alveolar sacs and less thickened interalveolar septa (Prussian blue, x400). d) section in the lung of a diabetic rat treated with SCs showing +ve staining of spindle cells (s) among alveoli, alveolar sacs and minimally thickened interalveolar septa (Prussian blue, x400). 


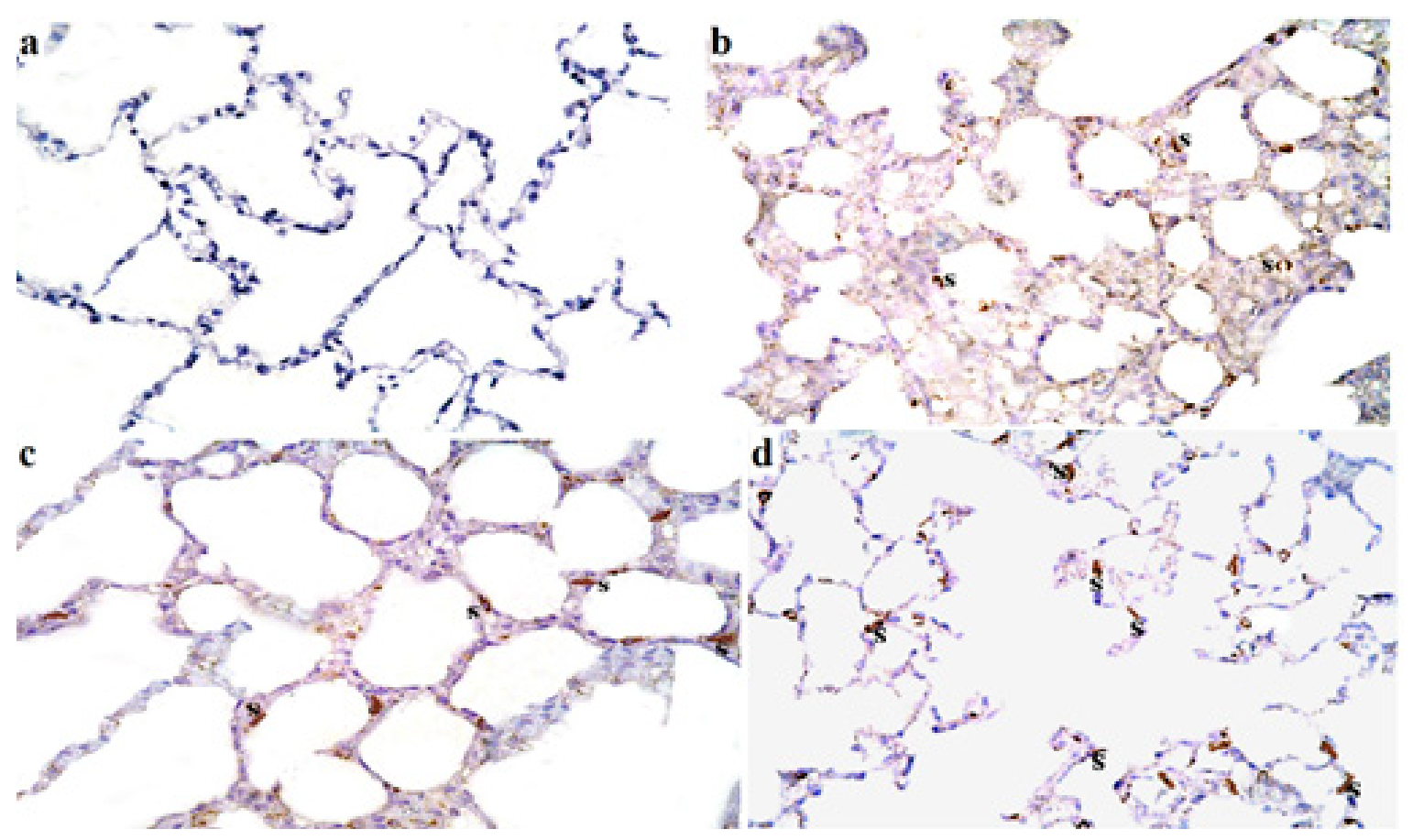

Plate (5): a) section in the lung of a control rat showing negative IE of CD105 in interalveolar septa (CD105 immunostaining, x400). b) section in the lung of a diabetic rat showing few CD105+ve spindle cells(s) in thickened interalveolar septa (CD105 immunostaining, x400).c) section in the lung of a diabetic rat treated with curcumin showing some CD105+ve spindle cells (s) in less thickened interalveolar septa (CD105 immunostaining, x400). d)section in the lung of a diabetic rat treated with SCs showing multiple CD105+ve spindle cells (s) in minimally thickened interalveolar septa (CD105 immunostaining, $\mathrm{x} 400)$.

\section{DISCUSSION}

The aim of the present study was designed to elucidate the possible ameliorative role of AMSCs and curcumin on the lung in STZ-induced type I diabetes of adult albino rat. Amelioration of diabetes induced changes in response to AMSCs and curcumin therapy was evidenced by histological, histochemical and immunohistochemical results and was confirmed by morphometric and biochemical results. Previous studies suggested that lung might be a target organ in type I diabetes, and its effect is either through direct effect or induction of inflammatory and fibrotic changes.

In the diabetic group, partial obliteration of the lumen, sometimes complete distortion of the bronchioles accompanied by thickening of the interalveolar septa were detected. These results were confirmed by a sig increase in the mean thickness of IAS. In accordance, obliterative bronchiolitis was due to bronchiolar wall injury by inflammatory cells and subsequently fibrous tissue proliferation ${ }^{[26]}$. Recently, inflammatory cell migration to the interalveolar and bronchoalveolar space is the key factor in the course of lung injury was recorded ${ }^{[27]}$.
A sig increase in the mean thickness of the wall of the pulmonary vessels were noted in diabetic group compared to the other group. These changes might lead to pulmonary hypertension. In support, collagen deposition affects vascular remodelling due to the collagen ability and/or collagen binding macromolecules to sequester growth factors and cytokines into the extracellular matrix, which is the major constituent of the vessel wall ${ }^{[28]}$.

Collagen fibers were increased in diabetic group compared to other groups; this confirmed by a sig increase in area $\%$ of CF. Concomitantly, a sig increase in STAT and SMAD genes. The pathogenesis of fibrosis and collagen deposition to transforming growth factor $\beta 1$ (TGF $\beta 1$ ) which is a known cytokine that control the immune responses during inflammation was explained ${ }^{[29]}$. During lung fibrosis, TGF $\beta 1$ activates lung fibroblasts and promotes epithelial mesenchymal transformations of different cell types, such as alveolar type II cells. Studies have demonstrated the role of STAT pathway activation in patient with lung fibrosis. TGFßR1 forms a protein complex that activates STAT pathway via SMAD protein ${ }^{[30]}$.

In the diabetic group a sig increase were found in 
L-hyp level as compared to the control, L-hyp is an important biomarker for idiopathic pulmonary fibrosis (IPF). The most common method for evaluating tissue fibrosis and collagen deposition is hydroxyproline quantification, L-Hydroxyproline is a major component of collagen, comprising around $13.5 \%$ of its amino acid composition $^{[31]}$.

In the diabetic group, a sig decrease was found in the count of CD105+ve cells compared to the therapy groups. The previous finding might be related to a sig increase of MDA and TNF- $\alpha$ with a significant decrease of GSH and CAT. TNF- $\alpha$ in lungs is an indicator of pulmonary inflammation and fibrosis. It can be concluded that diabetes induced inflammatory changes and oxidative stress ending in fibrosis which indicates unfavourable niche of SCs. These results were in agreement with a previous histopathological study which reported that, initial elevation in cytokines such as TNF- $\alpha$ in lung, is followed by increased expression of the profibrotic cytokine TGF- $\beta$ that induced a high oxidative stress and inflammation $^{[32]}$.

Regardless of cell origin and isolation technique, CD105 is a well-established MSC markers and indicating that they were of mesenchyme origin and specifically defined as ASC markers ${ }^{[33]}$. In the current work sig decrease in the count of CD105+ve cell in diabetic group compared to other group as mobilization of both stem cells and proangiogenic cells seems to be impaired in diabetics.

Concerning changes in curcumin treated group, it showed less thickening of the interalveolar septa compared to diabetic group with partial thickening of a vessel wall. Moreover, less dense infiltrating cells in the interalveolar septa were found with some normal alveoli and alveolar sacs. In support it was postulated that antidiabetic activity of curcumin might be due to its potent ability to suppress oxidative stress and inflammation. Curcumin also modulates the advanced glycation end products-induced complications of diabetes and the levels of glycosylated hemoglobin in diabetic rat ${ }^{[34]}$.

Morphological changes in curcumin group were confirmed biochemically by a sig decrease of MDA and sig increase of CAT and GSH compared to diabetic group. This improvement can be referred to its known antioxidant capacity. Additionally, curcumin attenuated $\mathrm{TNF} \alpha$ that showed sig decrease compared to diabetic group while sig increase compared to AMSCs and control group.

Different cell signalling pathways activated by TNF have been shown to be down-regulated by curcumin one of these include PI3K/Akt pathway alteration. However, the mechanism by which curcumin mediates these antiinflammatory effects in animals was not clear, but it was explained as curcumin blocked TNF production in cell culture and the expression of pro-inflammatory genes ${ }^{[35]}$

Minimal collagen fibers were detected in the IAS confirmed by a sig decrease in the mean area $\%$ of collagen fibers, in the mean thickness of pulmonary vessels wall and in the mean thickness of IAS compared to diabetic group. This demonstrates the antifibrotic role of curcumin which was in agreement with other authors, as they found that curcumin inhibit lung fibroblast proliferation and blocking transforming growth factor (TGF- $\beta 1$ ) signalling cascade ${ }^{[36]}$. The role of curcumin as an antioxidant and anti-inflammatory agent on rat lung was studied and the authors added that curcumin increased tissue levels of proteases like cathepsin which in turn will prevent collagen accumulation in a murine model of bleomycin-induced pulmonary fibrosis ${ }^{[37]}$.

A sig decrease in L-hyp level in curcumin group compared to diabetic group was detected in the current work, similarly, L-hyp content was studied in mice lung, and the authors concluded that L-hyp revealed a trend of decrease by approximately $10 \%$ after 21 days after curcumin therapy ${ }^{[36]}$.

In AMSCs treated group, apparently normal alveoli, few shed epithelial cells in the lumen of some bronchioles, congested arterioles and venules were noticed. These results were confirmed by a sig decrease of the IAS and thickening of the wall of blood vessels compared to diabetic and curcumin groups. Mesenchymal stem cells are multipotent cells that can differentiate into different cell lines and have immunomodulatory, antiproliferative, anti-fibrosis, anti-apoptosis, angiogenesis, growth factor production and anti-inflammatory effects. Their multipotency, migratory ability makes it the best therapeutic applications in chronic lung disease $\mathrm{e}^{[6]}$. Increased vascularity and congestion with SCT are very essential factors in the equation of regeneration. The congestion and angiogenesis induced by AMSCs is associated with better tissue healing was proved ${ }^{[38]}$.

In the present study the AMSCs treated group revealed a sig decrease of MDA and TNF- $\alpha$ while a sig increase of GSH and CAT as compared to the diabetic and curcumin groups. Early treatment with AMSCs may produce antagonists to TNF- $\alpha$ cytokines thus reduce the extent of lung inflammation as well as tissue healing by epithelial restoration ${ }^{[6]}$. These results were in agreement with the previous studies who stated that AMSCs decreased oxidative stress in the lung tissue and increased antioxidant activity as (GSH) by the secretion of soluble growth factors ${ }^{[39]}$. 
In AMSCs treated group, the collagen fibers were minimally detected in the IAS and around the pulmonary vessels compared to the diabetic and curcumin groups. This result was confirmed morphometrically by sig decrease in the mean area $\%$ of collagen fibers compared to other group that proved the benefit of AMSCs in the prevention of fibrosis. Going with, the early treatment with AMSCs is beneficial in prevention of lung fibrosis ${ }^{[40]}$.

Multiple Prussian's blue +ve cells were found around the congested blood vessels besides the thickened IAS. In agreement, following systemic administration of human ADSCs, they settled in the injured tissues of experimental rats ${ }^{[36]}$. This cell recruitment is essential for establishing beneficial effects of cell therapy, including enhanced functional and structural outcomes.

\section{CONCLUSION}

Diabetes induced inflammatory and fibrotic pulmonary changes that were ameliorated by curcumin therapy, and were more obviously ameliorated by AMSCs therapy.

\section{CONFLICT OF INTEREST}

There are no conflict of interests.

\section{REFERENCES}

1. Talakatta G, Sarikhani M, MuhamedJ, Dhanya K, Somashekar BS, Mahesh PA, Sundaresan N, Ravindra PV. Diabetes induces fibrotic changes in the lung through the activation of TGF- $\beta$ signaling pathways. Sci Rep. 2018;8(1):11920-11935.

2. Vendrame F, Hopfner YY, Diamantopoulos S, Virdi SK, Allende G, Snowhite IV, Reijonen HK, Chen L, Ruiz P, Ciancio G, Hutton JC, Messinger S, Burke GW , Pugliese A. Risk Factors for Type 1 Diabetes Recurrence in Immunosuppressed Recipients of Simultaneous Pancreas-Kidney Transplants. Am J Transplant. 2016; 16(1):235-45.

3. Murai N, Ohtaki H, Watanabe J, Xu Z, Sasaki S, Yagura K, Shioda S, Nagasaka S, Honda K, Izumizaki M. Intrapancreatic injection of human bone marrowderived mesenchymal stem/stromal cells alleviates hyperglycemia and modulates the macrophage state in streptozotocin-induced type1diabeticmice. PLoS One. 2017;12(10): e0186637.

4. Guo Y, Xiao Z, Wang Y, Yao W, Liao S, Yu B, Zhang J, Zhang Y, Zheng B, Ren B, Gong Q. Sodium Butyrate Ameliorates Streptozotocin-Induced Type 1 Diabetes in Mice by Inhibiting the HMGB1 Expression. Front Endocrinol (Lausanne). $2018 ; 9: 630$.
5. Zhang W, Schmull S, Du M, Liu J, Lu Z, Zhu H, Xue S, Lian F. Estrogen Receptor $\alpha$ and $\beta$ in Mouse: AdiposeDerived Stem Cell Proliferation,Migration, and Brown Adipogenesis In Vitro.Cell Physiol Biochem. 2016;38(6):2285-2299.

6. Maltaib Z, Emansy A, Elmahlawy AM, Sabry D. The Possible Ameliorative Effect of Mesenchymal Stem Cells and Curcumin On bleomycin Induced Lung Injuries in the Adult Male Rats: Histological and Immunohistochemical Study. Journal of J Stem Cell Research \& Therapy.2017;7(6):389-402.

7. Ahangarpour A, Shabani R, Farbood Y. The effect of betulinic acid on leptin, adiponectin, hepatic enzyme levels and lipid profiles in streptozotocinnicotinamide-induced diabetic mice. Res Pharm Sci. 2018 Apr; 13(2): 142-148.

8. Aboul-Fotouh GI, Zickri MB, Metwally HG, Ibrahim IR, Kamar SSI. Comparative Study on the Therapeutic Effect of Atorvastatin and Stem Cells on Amiodarone Induced Lung Injury in Male Rat. Int J Stem Cells. 2016;8(2):170-180.

9. Rahmani AH, Alsahli MA, Aly SM, Khan MA, Aldebasi YH. Role of Curcumin in Disease Prevention and Treatment. Adv Biomed Res. 2018;7:38.

10. Iranpour FG, Kheiri S. Coadministration of calcium chloride with lead acetate can improve motility of cauda epididymal spermatozoa in Swiss white mice. Int J Reprod. BioMed. 2016;14(2): 141-144.

11. Ozmen J, Bobryshev YV, Lord RS, Ashwell KW. Identification of dendritic cells in aortic atherosclerotic lesions in rats with diet induced hypercholesterolaemia. Histol Histopathol 2002;17: 223-237.

12. Kiernan JK. Histological and Histochemical methods. In: Theory and practice. 3rd ed, Arnold Publisher, London, New York and New Delhy 2001; 111-162.

13. Bancroft JD, Gamble M. Connective tissue stains. In: Theory and Practice of Histological Techniques, sixth edition. Elsevier Health Sciences, Churchill Livingstone, Edinburgh, London, Oxford, New York, Philadelphia, St Louis, Sydney and Toronto; 2008:161-186.

14. Rossi G, Cavazza A, Spagnolo P, Bellafiore S, Kuhn E, Carassai P, Caramanico L, Montanari G, Cappiello G, Andreani A, Bono F, Nannini N.The role of macrophages in interstitial lung diseases: Number 3 in the Series "Pathology for the clinician" Edited by Peter Dorfmüller and Alberto Cavazza. Eur Respir Rev. 2017;26 145. 
15. Yagi $H$, Soto-Gutierrez A, Navarro-Alvarez $N$, Nahmias Y, Goldwasser Y, Kitagawa Y, Tilles AW, Tompkins RG, Parekkadan B, Yarmush ML. Reactive bone marrow stromal cells attenuate systemic inflammation via sTNFR1. Mol Ther 2010;18:1857-1864.

16. Brancaccio P, Lippi G, Maffulli N. Biochemical markers of muscular damage. Clin Chem Lab Med 2010; 48(6):757-767.

17. Chen X, Zhang X, Zhang J, Gao Y, Yang Z, Li S, Dai $\mathrm{H}$. Attenuation of acute lung injury in a rat model by Semen Cassiae. BMC Complement Altern Med. 2017;17(1):234-241.

18. Terashima H, Aonuma M, Tsuchida H, Sugimoto K, Yokoyama M, Kato M.. Attenuation of pulmonary fibrosis in type I collagen-targeted reporter mice with ALK-5 inhibitors. Pulm Pharmacol Ther. 2019;54:31-38.

19. NatarajanK, MeganathanV, MitchellC, BoggaramV. Organicdustinducesinflammatory gene expressionin lung epithelial cells via ROS-dependent STAT-3 activation.Am J Physiol Lung Cell Mol Physiol. 2019;317(1):L127-L140.

20. Pu T, Guo P, Qiu Y, Chen S, Yang L, Sun L, Ye F, Bu $\mathrm{H}$. Quantitative real-time polymerase chain reaction is an alternative method for the detection of HER-2 amplification in formalin-fixed paraffin-embedded breast cancer samples. Int J Clin Exp Pathol 2015; 8(9): 10565-10574.

21. Ma T, Gong K, Ao Q, Yan Y, Song B, Huang H, Zhang X, Gong Y. Intracerebral transplantation of adipose-derived mesenchymal stem cells alternatively activates microglia and ameliorates neuropathological deficits in Alzheimer's disease mice. Cell Transplant 2013;22 Suppl 1:S113-S126.

22. Kraitchman DL, Heldman AW, Atalar E, Amado LC, Martin BJ, Pittenger MF, Hare JM, Bulte JW. In vivo magnetic resonance imaging of mesenchymal stem cells in myocardial infarction. Circulation $2003 ; 107: 2290-2293$

23. Sun J, Liu WH, Deng FM, et al. Differentiation of rat adipose-derived mesenchymal stem cells into corneallike epithelial cells driven by PAX6. Exp Ther Med. 2018;15(2):1424-1432.

24. Haasters F, Prall WC, Anz D, Bourquin C, Pautke C, Endres S, Mutschler W, Docheva D, Schieker M. Morphological and immunocytochemical characteristics indicate the yield of early progenitors and represent a quality control for human mesenchymal stem cell culturing. J Anat 2009;214:759-767.

25. Emsley R, Dunn G, White I. Mediation and moderation of treatment effects in randomized controlled trials of complex interventions. Stat Methods Med Res 2010;19(3): 237-270.

26. Epler GR. Diagnosis and treatment of constrictive bronchiolitis. F1000 Med Rep.2010; 2 (32):1-5.

27. Park I, Kim M, Choe K, Song E, Seo H, Hwang Y, Ahn J, Lee SH, Lee JH, Jo YH, Kim K, Koh GY, Kim P. Neutrophils disturb pulmonary microcirculation in sepsis-induced acute lung injury. Eur Respir J. 2019 Mar 28;53(3).

28. Macri L, Silverstein D, Clark RAF. Growth factor binding to the pericellular matrix and its importance in tissue engineering. Adv Drug Deliv Rev. 2007; 59:1366-1381.

29. Milara, J, Hernandez G, Ballester B, Morell A, Roger I, Montero P, Escrivá J, Lloris JM, MolinaMolina M, Morcillo E, Cortijo J. The JAK2 pathway is activated in idiopathic pulmonary fibrosis. Respir. Res.2018;19(1): 24.

30. Tang LY, Heller M, Meng Z, Yu L R, Tang Y, Zhou $M$, Zhang YE.Transforming Growth Factor- $\beta$ (TGF- $\beta$ ) directly activates the JAK1-STAT3 axis to induce hepatic fibrosis in coordination with the SMAD pathway.J. Biol. Chem. 2017; 292, 4302-4312.

31. Ren Y, Zhao J, Shi Y, Chen C, Chen X, Lv C. Simple determination of L-hydroxyproline in idiopathic pulmonary fibrosis lung tissues of rats using nonextractive high-performance liquid chromatography coupled with fluorescence detection after pre-column derivatization with novel synthetic 9-acetylimidazolcarbazole. J Pharm Biomed Anal. 2017;142:1-6.

32. Mousa AM. Effect of pirfenidone on bleomycin induced pulmonary alveolar fibrosis in adult male rats. Histological, immunohistochemical, morphometrical and biochemical study. IJCDA. 2016;(2): 217-223.

33. Bourin, P. et al. Stromal cells from the adipose tissue-derived stromal vascular fraction and culture expanded adipose tissue-derived stromal/stem cells: a joint statement of the International Federation for Adipose Therapeutics and Science (IFATS) and the International Society for Cellular Therapy (ISCT). Cytotherapy 15, 641-648 (2013).

34. Nabavi SF, Thiagarajan R, Rastrelli L, Daglia M, Sobarzo-Sánchez E, Alinezhad H, Nabavi 
SMCurr. Curcumin: a natural product for diabetes and its complications. Top Med Chem. 2015;15(23):2445-255.

35. Jobin C, Bradham CA, Russo MP, Juma B, Narula AS, Brenner DA, et al. Curcumin blocks cytokinemediated NF-kappa B activation and proinflammatory gene expression by inhibiting inhibitory factor I-kappa B kinase activity. J Immunol. 1999;163:3474-3483.

36. Smith MR, Gangireddy SR, Narala VR, Hogaboam CM, Standiford TJ, Christensen PJ, Kondapi AK, Reddy RC: Curcumin inhibits fibrosis-related effects in IPF fibroblasts and in mice following bleomycininduced lung injury. Am J Physiol Lung Cell Mol Physiol. 2010, 298 (5): 616-625.

37. Zhang $\mathrm{D}$, et al. Antifibrotic effects of curcumin are associated with overexpression of cathepsins $\mathrm{K}$ and $\mathrm{L}$ in bleomycin treated mice and human fibroblasts. Respir. Res. 2011;12:154. doi: 10.1186/1465-9921-12-154.

38. Abd El Azeem AF, Al-Ahmadyb HM, Abdul Rahmana MA, Abdel Hameed MA, Shaalan OF. Angiogenesis induced by autologous whole bone marrow stem cells seeded on collagen scaffolds in silicone nerve tubes. An experimental study. Tanta Dental J 2014;111:227-234.

39. El-Attar S, Elsayed LA, Rashed L. Role of stem cells and antioxidant on modulation of body defense mechanism in lipopolysaccharide-induced acute lung injury in rats. Med J Cairo Univ. 2012; 80: 559-573.

40. Castiglione F, Hedlund P, Van der Aa F, Bivalacqua TJ, Rigatti P, Van Poppel H, Montorsi F, De Ridder $\mathrm{D}$, Albersen M. Intratunical injection of human adipose tissue-derived stem cells prevents fibrosis and is associated with improved erectile function in a rat model of Peyronie's disease. Eur Urol. 2013;63:551-560. 
الملخص العربى

الدورالوقائى المحتمل للخلايا الجذعية والكركم على الرئة في داء السكري من النوع الأول المستحث

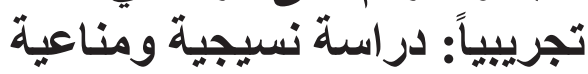

أماني السبا محمد موسي حمود1 ـهالة جبر متولى 2

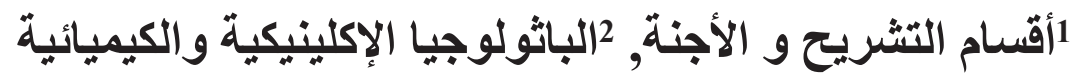

كلية الطب , جامعة القاهرة

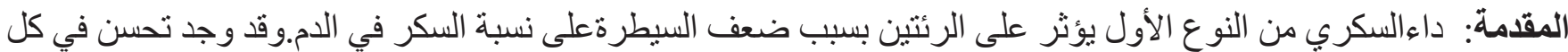

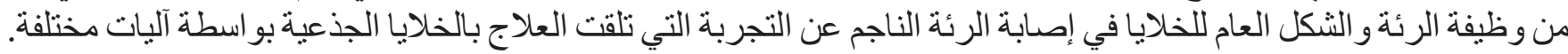

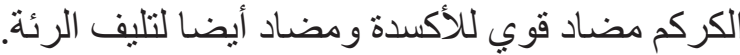

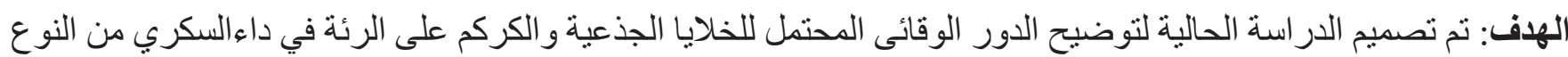

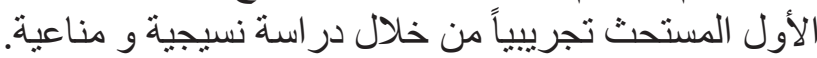

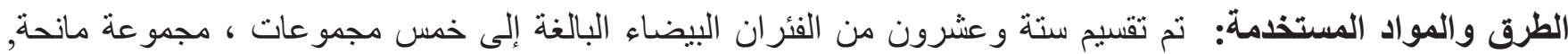

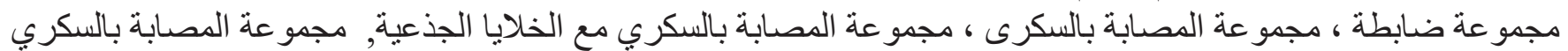

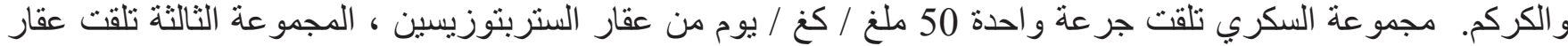

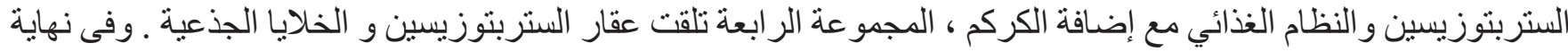

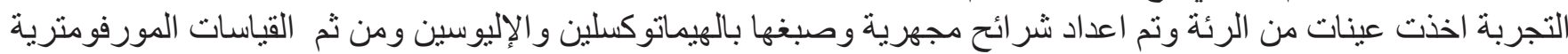
و الكيميائية الحيوية و الإحصائية.

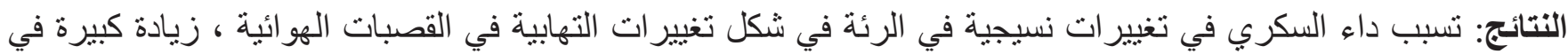

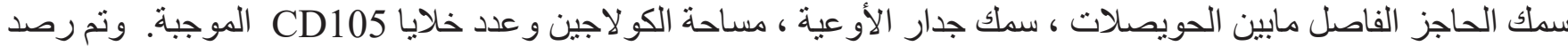

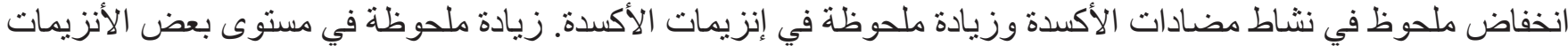

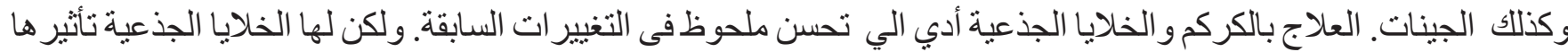

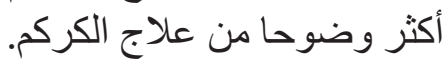
الاستنتاج: مرض السكري الناجم عن إصابات الرئة في الفئران التي تم تحسينها من قبل الكركم، ولكن الخلايا الجذعية تأثير ها أكثر وضوحا من علاج الكركم. 